\title{
Biodegradation of aniline by alkaliphilic strain Bacillus badius D1
}

\author{
Vasudeo Sarwade, Kachru Gawai* \\ Biochemistry Division, Department of Chemistry
}

\begin{abstract}
Aromatic amines are well known for their properties as potential mutagens as well as carcinogens. Aniline is an aromatic amine and it is used as an intermediate of many synthetic organic compounds. Several azo dyes and nitro amine compounds, on degradation produce aniline which causes environmental pollution. In the present study, attempts were made to investigate biodegradation of aniline by using an alkaliphile, Bacillus badius D1 strain with various concentrations ranging from 0.28 to $1.55 \mathrm{~g} / \mathrm{L}$ at $37^{\circ} \mathrm{C}$ under shaking condition at pH 9. The alkaliphile, Bacillus badius D1 strain was found to have promising degradation potential towards aniline. The effect of various parameters such as, temperature, $\mathrm{pH}$, salinity and additional carbon and nitrogen sources showed significant increase in degradation. The degradation process of aniline by bacteria was monitored by spectroscopic analysis at various time intervals. The tentative degradation pathway was established from the structures of intermediates of aniline by ${ }^{l} H N M R$, FTIR and GCMS.
\end{abstract}

Key words: Biodegradation, Bacillus badius, Aniline

Abbreviations: , $m M$ : milli moles , $\mu l$ : micro liter, SOD- superoxide dismutase

\section{Introduction:}

Alkaliphiles are the organisms thriving in harsh alkaline conditions. Although alkaliphiles are being employed for environmental cleanup [1-6], the literature regarding the study of aromatic amines or aniline degradation is less reported as compared to the other degradation studies. The present study is planned to examine the degradation potential of alkaliphile, Bacillus badius D1 strain towards aniline. Most of the industrial waste is alkaline in nature which is generally not degraded by neutrophiles and imparts potential threat to the environment. Organic compounds like azo dyes, Nitro amines lead to form aniline as one of the catabolic intermediate. Monocyclic aromatic amines are environmental pollutants and are genotoxic. These impose hazards to human health and aniline is one of them. It is being released into the soil and water bodies due to its expanded use in an industry [7]. Aniline is a synthetic organic compound used in dyes, herbicides and medicines. It is the most important intermediate used in polyurethane, rubber and agricultural products. Aniline cancer had been detected in dye workers particularly as a bladder cancer. Aniline is weak aromatic base; it remains stable in alkaline conditions and adversely affects the aquatic system. Azo dyes on biotransformation produce aromatic amines like p-phenylene diamine, benzedene or aniline. Aniline induces intra chromosomal recombination between repeated sequences in Saccharomyces cerevisiae, resulting in deletion (DEL) of intervening sequences. It has reported that the generation of oxidative free radical species by aniline and/or its metabolites may be responsible for its recombinagenic activity in the yeast. Aniline cytotoxicity was many-fold increased in the strains of $S$.cerevisiae lacking the antioxidant enzyme superoxide dismutase [8]. As aniline is highly toxic, it damages the balance of the ecosystem. Alkaliphiles grow well in alkaline conditions and the organic pollutants could be utilized by these bacteria as carbon and nitrogen source.

\section{Materials and methods:}

2.1 Chemicals and reagents: Aniline $98 \%$ pure, ethyl acetate and chloroform methanol (SRL, Mumbai, India) Peptone, Yeast extract, Agar (Hi-media, Mumbai, India)

\subsection{Media preparation:}

The broth media used for biodegradation study consist of yeast extract, peptone, $\mathrm{NaCl}-5 \mathrm{~g} / \mathrm{L}$ respectively. The micronutrients' in mg / $\mathrm{L}$ were $\mathrm{KH}_{2} \mathrm{pO}_{4}-170, \mathrm{Na}_{2} \mathrm{HPO}_{4}-290$, (NH4) ${ }_{2} \mathrm{SO}_{4}-100, \mathrm{MgSO}_{4}, \mathrm{MgO}-$ $0.1, \mathrm{FeSO}_{4}-0.05, \mathrm{CaCO}_{3} 0.20, \mathrm{ZNSO}_{4} 0.08, \mathrm{CuSO}_{4}$ 0.016, $\mathrm{CaSO}_{4}$, Boric Acid 0.06, pH-9. The media were sterilized by autoclaving at $121{ }^{\circ} \mathrm{C}$ at $15 \mathrm{psi}$ for $20 \mathrm{~min}$. The solid media were prepared in the same way by adding $2 \%$ agar.

\subsection{Experimental setup:}

2.3.1 Bacterial strain adaptation: Alkaliphilic Bacillus badius D1strain isolated by standard method like serial dilution. It was screened for aniline degradation and further adapted [9] for enhancing more potential of degradation by adding more aniline aseptically in broth media around 3 months. 
2.3.2 Biodegradation studies on Aniline: Thirteen $500 \mathrm{ml}$ Conical flasks containing Sterilized $250 \mathrm{ml}$ alkaline broth pH-9 were inoculated by $1 \%$ Bacillus badius culture possessing $1.6 \mathrm{OD}$ at $600 \mathrm{~nm}$ aseptically and grown for $24 \mathrm{hrs}$ at $37{ }^{\circ} \mathrm{C}$ with shaking on Orbital shaker at $110 \mathrm{rpm}$. The $24 \mathrm{hrs}$ grown culture flasks were induced by adding appropriate concentration of aniline. These flasks were removed sequentially from 0 to 72 hours from a 6 hour interval. The removed flasks were used for OD at $600 \mathrm{~nm}$ to check the growth and then spun to DuPont Sorvoll Cold centrifuge at $10000 \mathrm{x}$ g. An aliquot of centrifuged supernatant used for quantitative analysis by diazo coupling with N-1- Napthyl ethylenediamine. Remaining part was used for solvent extraction. The residue obtained after Rota evaporation used for UV-visible spectroscopic studies, further it was purified by preparative TLC or column chromatography using neutral alumina. The purified residue was further subjected to FTIR, ${ }^{1} \mathrm{HNMR}$ and GC-MS for structural determination. Similarly another flask with same media was kept as abiotic control by adding the appropriate concentration of aniline aseptically without bacterial culture and aliquots were used for quantitative analysis with respect to the time intervals. All experiments were carried in the dark.

\subsection{Enzyme Activities:}

2.4.1 Preparation of Cell extract: Cell mass was harvested after 24 hours induction with aniline by

Du-Pont Sorvall RC-5B centrifuge by spinning at $10000 \mathrm{x}$ g for $15 \mathrm{~min}$ at $4{ }^{\circ} \mathrm{C}$. The cell mass was washed with phosphate buffer $\mathrm{pH} 8.0$ twice and physiological saline. Cell disruption was carried by sonicator Ultra O Sonic (Mumbai) in the same buffer. The resulting homogenate was centrifuged in cold condition at $15000 \mathrm{xg}$ for 20 min. The cytosolic protein was measured by Lowry [10] using BSA as standard.

2.4.2 Cytosolic content of Cytochrome P-450: The content of cytosolic cytochrome P 450 was measured by the procedure of Oura and Sato $[11,12]$. The content of CYP -450 calculated by using $91 \mathrm{~cm}^{-1} \mathrm{mM}^{-1}$ as an extinction coefficient. All operations were carried at room temperature. CYP 450 content was reported as $n$ mole of CYP $450 \mathrm{mg}^{-1}$ of cytosolic protein.

2.4.3 Super Oxide Dismutase [SOD]: SOD was measured spectrophotometrically according to the procedure of Mishra and Fridovich [13] on Jasco V-630 double beam spectrophotometer at room temperature. The inhibition of auto-oxidation of epinephrine at $\mathrm{pH} 10.2$ by SOD was monitored by measuring the formation of androchrome at $480 \mathrm{~nm}$.

2.4.4 Acetanilide hydroxylase assay: Acetanilide hydroxylase was assayed by the protocol of Shenkman et al, [14]. The p-hydroxy acetanilide formed during the hydroxylation of acetanilide was measured according to the method of Weiseberg and Goodall [15]. The activity of the enzyme was expressed as n moles of p- hydroxyl acetanilide formed / $\mathrm{min} / \mathrm{mg}$ of cytosolic protein.

2.4.5 Catechol 1, 2 Dioxygenase: catechol 1, 2 dioxygenase activity was studied by Guzik Urszula, Gren Izabela et al [16] 'The enzyme activity was expressed as $\mu \mathrm{M} / \mathrm{min} / \mathrm{mg}$ of protein.

2.4.6 Catechol 2, 3 Dioxygenase: catechol 2, 3 dioxygenase activity was studied by J.M Sala Trepat and W.C. Evans $[17,18]$. The enzyme activity noted as $\mu \mathrm{M} / \mathrm{min} / \mathrm{mg}$ of protein.

2.4.7 Quantification of aniline: Remaining residual aniline during the microbial degradation was determined by the procedure of George Norvit [19].

\section{Results:}

3.1 Degradation of aniline by Bacillus badius $D 1$ at concentration of $1.55 \mathrm{~g} / \mathrm{L}$ with different time intervals.

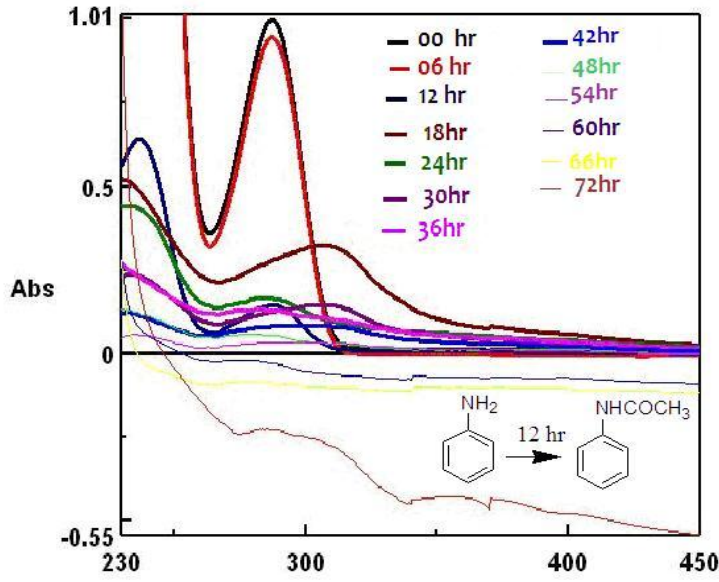

Fig. 1 UV- visible pattern of aniline degradation by Bacillus badius D1 
Fig. 1 indicates that the degradation pattern of aniline by Bacillus badius D1, aniline at a concentration of $1.55 \mathrm{~g} / \mathrm{L}$ was incubated with bacterial strain at $\mathrm{pH} 9.0$ up to 72 hours. The pattern of degradation was monitored by spectroptometer at each 6 hour of interval. The peak at $288 \mathrm{~nm}$ was found to be decreased by $6 \mathrm{hr}$ incubation and new peak was detected at $235 \mathrm{~nm}$ by the end of 12 hour incubation. Another peak at $275 \mathrm{~nm}$ was observed at the end of 24 hour incubation, indicating the possibility of catechol. Further incubation up to 72 hours resulted in maximum utilization of aniline by the experimental bacteria.

\subsection{Effect of concentrations on degradation of aniline.}

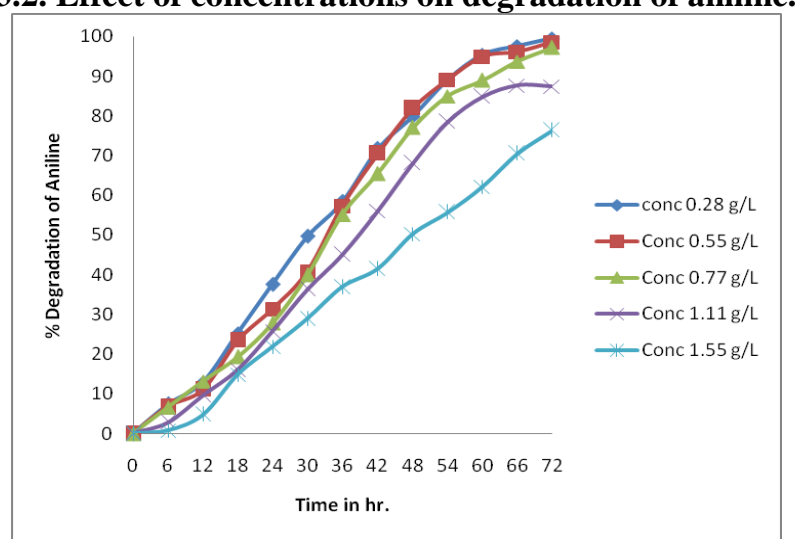

Fig. 2 Effect of concentrations on aniline degradation

Fig. 2 depicts the effect of various concentrations of aniline on the degradation. Aniline at various concentrations $(0.28$ to $1.55 \mathrm{~g} / \mathrm{L})$ was incubated with bacteria for 72 hours. At concentrations of 0.28 and 0.55 $\mathrm{g} / \mathrm{L}$ maximum degradation of aniline $99 \%$ was observed within 72 hours. With an increase in concentration of aniline the degradation rate was found to be lowered $78 \%$ up to 72 hours.

3.3. Effect of $\mathbf{p H}$ on aniline degradation:

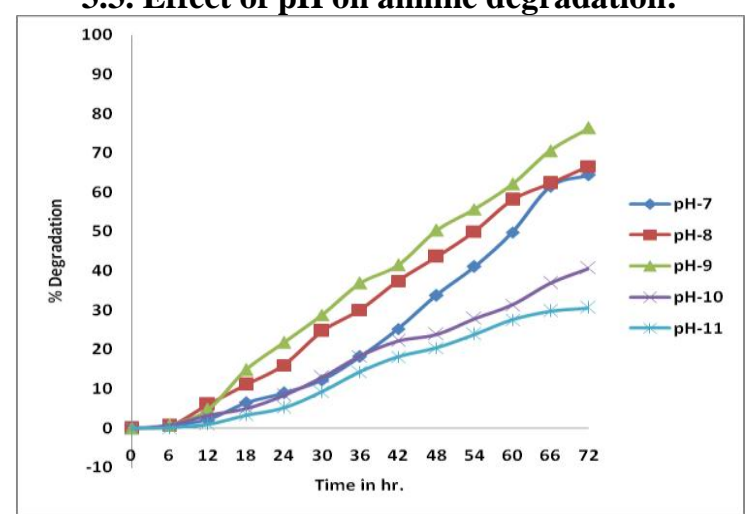

Fig. 3 Effect of $\mathrm{pH}$ on aniline degradation

Fig. 3 shows the effect of $\mathrm{pH}$ on the degradation of aniline by Bacillus badius D1. In order to examine the effect of $\mathrm{pH}$ on the degradation of aniline by this bacterial strain, Bacillus badius D1 was incubated with aniline at a concentration of $1.55 \mathrm{~g} / \mathrm{L}$ for 72 hours. At $37{ }^{\circ} \mathrm{C}$ with $\mathrm{pH}$ range $7.0-11$. Approximately $78 \%$ of aniline was degraded at $\mathrm{pH}$ 9.0. A further increase in the $\mathrm{pH}$ values the rate of aniline degradation was found to be reduced marginally.

\subsection{Effect of Temperature on aniline degradation:}

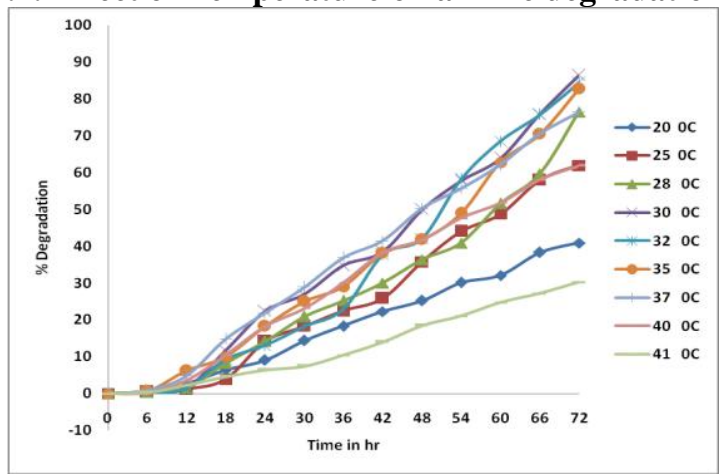

Fig. 4 Effect of Temperature on aniline degradation 
Fig. 4 shows the effect of temperature on the degradation of aniline by Bacillus badius D1 to observe the effect of temperature on aniline degradation, alkaliphilic strain Bacillus badius D1 was incubated with aniline at a concentration of $1.55 \mathrm{~g} / \mathrm{L}$ for 72 hours at various temperatures i.e. $20-40{ }^{0} \mathrm{C}$. The maximum degradation of aniline was observed at a $30{ }^{\circ} \mathrm{C}$. Further increase in the temperature resulted in the slight decrease of aniline degradation.

\subsection{Effect of Salinity:}

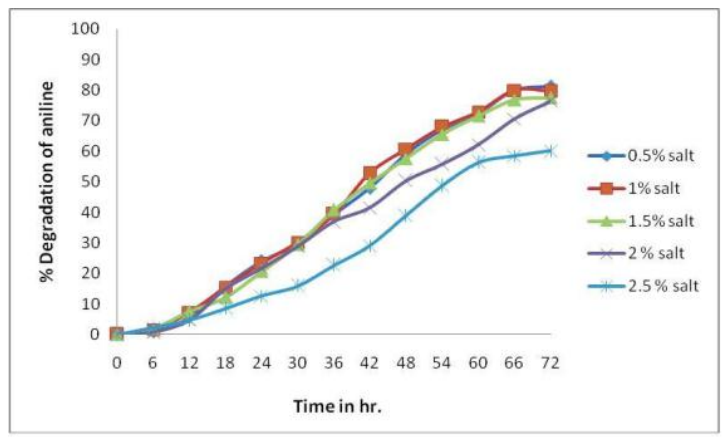

Fig. 5 Effect of Salinity

Fig. 5 indicates the effect of salinity on aniline degradation. The saline tolerant bacterial strain Bacillus badius D1 was incubated with aniline at $1.55 \mathrm{~g} / \mathrm{L}$ of growth medium, $\mathrm{pH} 9.0$ at $37{ }^{0} \mathrm{C}$ for 72 hours with $\mathrm{NaCl}$ concentration ranging from $0.5 \%$ to $2.5 \%$. The maximum degradation of aniline $(90 \%)$ was observed between $0.5-1 \%$ of $\mathrm{NaCl}$ with an increase in $\mathrm{NaCl}$ concentration up to $2.5 \%$ in media decreases the rate of degradation of aniline marginally.

\subsection{Effect of additional carbon sources on aniline degradation:}

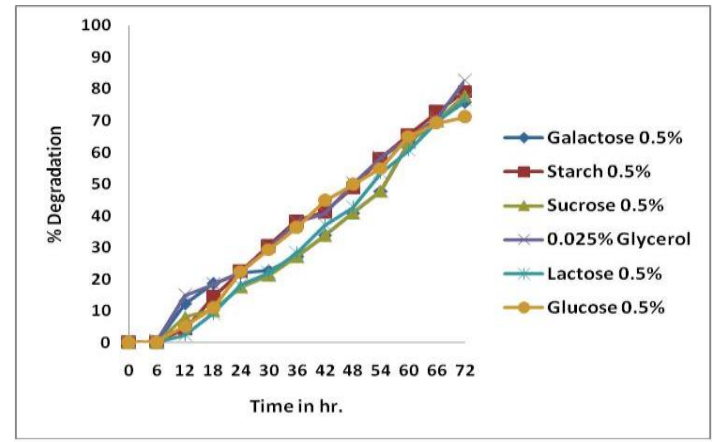

Fig. 6: Effect of additional carbon sources on aniline degradation

The effect of additional carbon sources on aniline degradation is shown in Fig. 6. On incubation of bacterial strain Bacillus badius D1 in broth medium having aniline concentration $1.55 \mathrm{~g} / \mathrm{L}$ with different carbon sources like galactose, starch, sucrose, lactose, glucose etc at $0.5 \%$ and glycerol $0.025 \%$ at temperature $37{ }^{\circ} \mathrm{C}$, $\mathrm{pH} 9.0$ for $72 \mathrm{hr}$. It was observed that in the presence of all these carbon sources maximum degradation $(90 \%)$ of aniline was observed.

\subsection{Effect of additional Nitrogen source:}

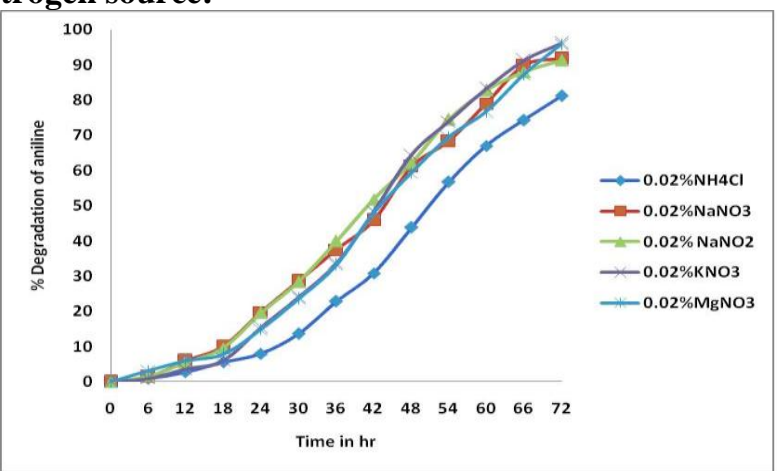

Fig. 7 Effect of additional Nitrogen source 
The effect of additional Nitrogen source is indicated in Fig. 7. To examine the effect of various nitrogen sources on the degradation of aniline by Bacillus badius D1, the bacterial strain was incubated with $1.55 \mathrm{~g} / \mathrm{L}$ aniline in growth medium, $\mathrm{pH} 9.0$ at $37{ }^{\circ} \mathrm{C}$ for 72 hours with several nitrogen sources such as $\mathrm{NH}_{4} \mathrm{Cl}_{1} \mathrm{NaNO}_{3}$, $\mathrm{NaNO}_{2}, \mathrm{KNO}_{3}$, and $\mathrm{MgNO}_{3}$ at $0.02 \%$. All the added nitrogen sources have supported the degradation of aniline.

\subsection{Effect of aniline on various microbial enzyme activities:}

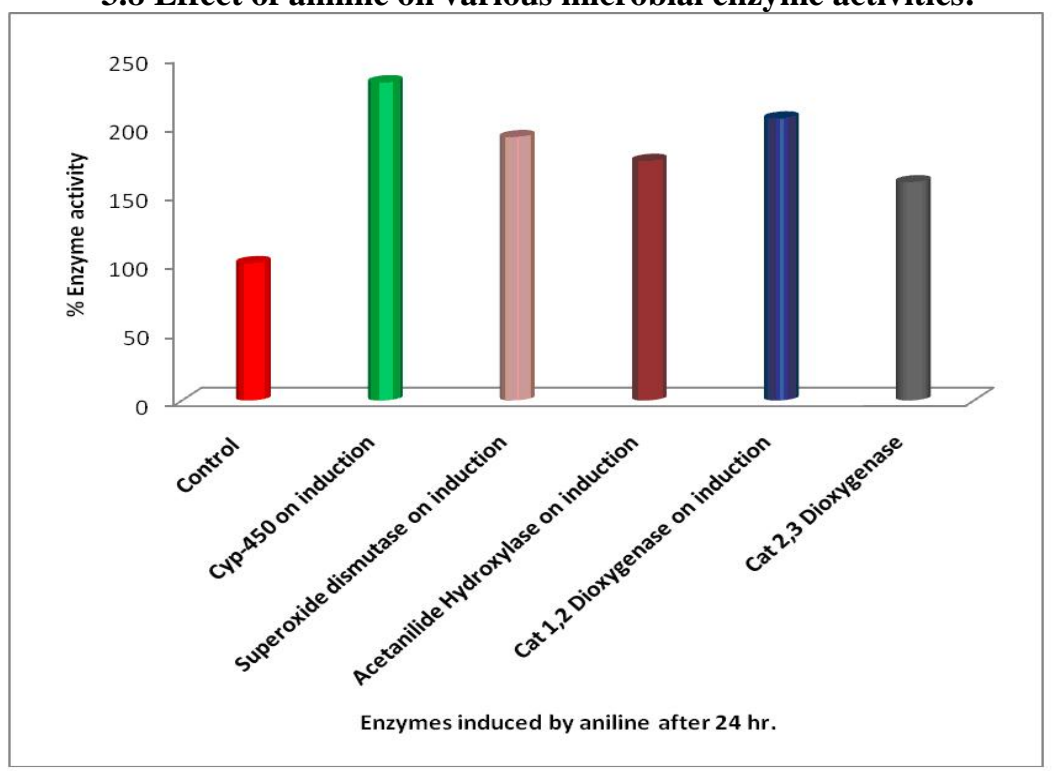

Fig. 8 Effect of aniline on various microbial enzyme activities

Fig. 8 shows the effect of aniline on the activities of microbial biotransformation enzymes. To evaluate the effect of aniline on these biotransformation enzymes, bacterial strain Bacillus badius D1 was incubated with aniline at a concentration of $1.55 \mathrm{~g} / \mathrm{L}$, for 24 hours at $37{ }^{\circ} \mathrm{C}$, in growth media $\mathrm{pH} 9.0$. Incubation with aniline for 24 hours was resulted in an increase in the content of cytosolic cytochrome P450 and in the activities of acetanilide hydroxylase, super oxide dismutase, Catechol 1,2 dioxygenase and cortical 2,3 dioxygenase as compared to their respective controls. However, the magnitude of increase in the content of cytochrome P450 and the activities of superoxide dismutase, catechol 1, 2 dioxygenase were found to be higher than acetanilide hydroxylase and catechol 2, 3 dioxygenase.

\subsection{Spectroscopic analysis of intermediate metabolites during aniline degradation by Bacillus badius D1:}

The structural analysis of isolated metabolites/intermediates of aniline at each time interval of 6 hours is determined by, NMR, FTIR, and GCMS. The formation of acetanilide was confirmed by delta values from NMR $\delta$ - 2.151,(S-3H), $\delta-7.5,(\mathrm{~m}-2 \mathrm{H})$, FTIR stretches at 1662,1498-1535,3294, the mass spectrographic data. The molecular ion peak appeared at 135 and fragmentation peaks at 93, 77, 66, 43, and 40. The metabolite acetanilide was isolated at the end of 12 hour incubation. Acetanilide was further transformed to catechol by the bacterial strain Bacillus badius at the end of 24 hours incubation. The confirmation was made by NMR data $\delta$ $5.33(\mathrm{~S}-2 \mathrm{H}), \delta-6.8(\mathrm{~m}-4 \mathrm{H})$, FTIR Ar-OH-3229, Ar-1517-159 and mass spectrographic data showing molecular ion peak at 110 and its fragmentation observed at 92, 80, 64, 53, 40. Catechol was further converted into cis -cis muconic acid at the end of 48 hours. The metabolite structure was confirmed by NMR delta values $\delta$-12.9 (S$2 \mathrm{H}), \delta-6.21(2-\mathrm{H}), \delta-7.59(2 \mathrm{H})$, the FTIR stretches observed at Ar-COOH - b-3043-2575,Ar-1635-1674, while mass spectrographic data indicated the molecular ion peak at 142 and the fragmentation pattern appeared at $142,123,114,96,83,71,56,43,38$. 


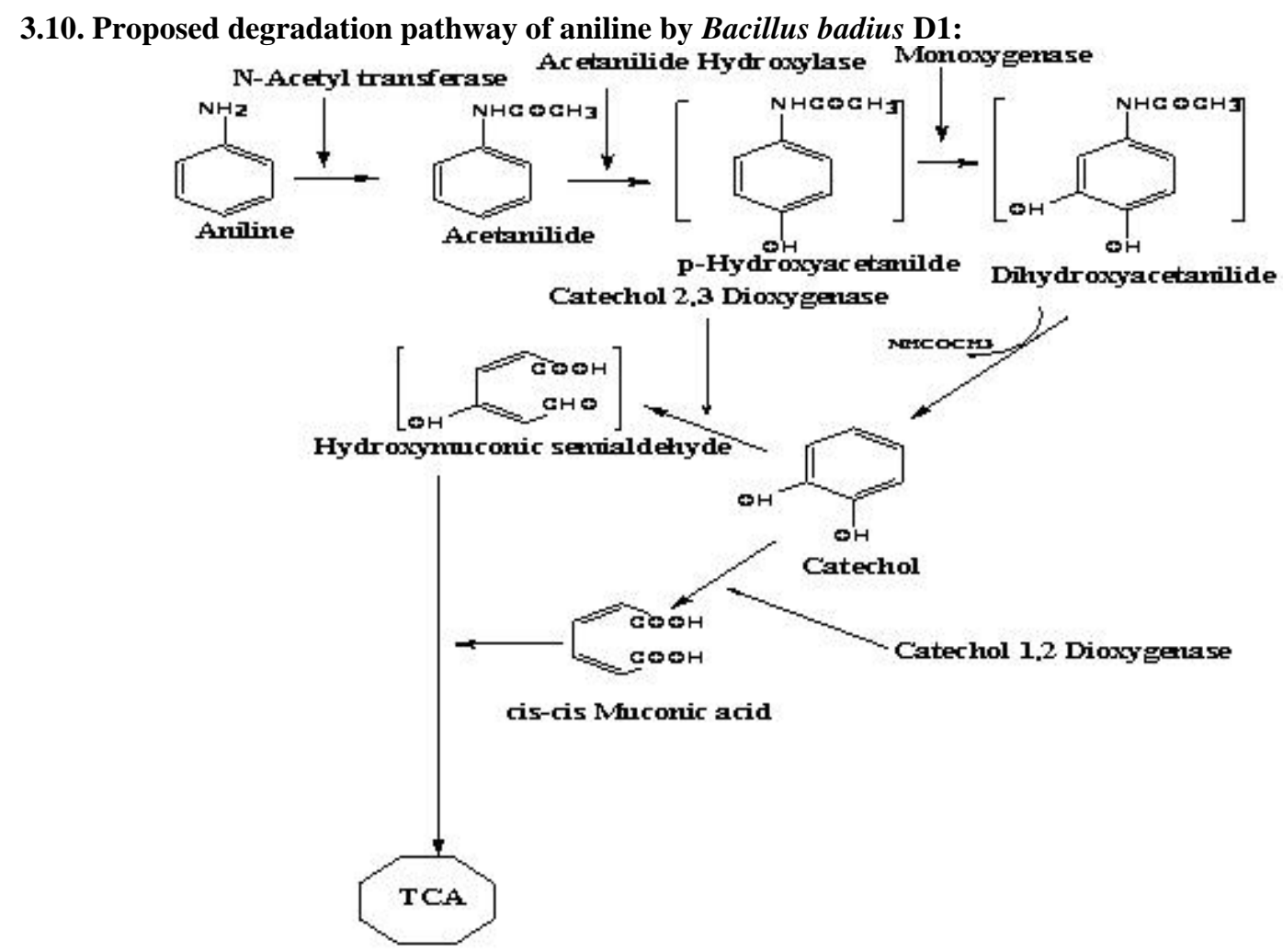

Fig. 9: Proposed degradation pathway of aniline by Bacillus badius D1

The parent molecule aniline was transformed to acetanilide, p-hydroxy and dihydroxy acetanilide, catechol and cis-cis muconic acid finally muconic acid enters into TCA cycle. The biotransformation of aniline could be attributed to the involvement of microbial enzymes like $\mathrm{N}$ - acetyl transferase, Acetanilide hydroxylase, monoxygenase, catechol 1,2 dioxygenase and catechol 2, 3 dioxygenase.

\section{Discussion}

Environmental pollutants and wide range of toxic organic compound accumulates in the environment affects all types of ecosystems, which is the repercussion of anthropogenic activities like efflux of industrial inputs impacted seriously on the pristine nature of our environment. At present, it is estimated that more than 100 million people are at the risk from toxic pollutants above the international levels and above the international health standards [20]. Various types of microorganisms such as bacteria, fungi and algae are present in the soil as well as in the aquatic ecosystem. Most of these microorganisms are eco-friendly and few of them are also known as pathogens. Microbial metabolism potential provides a safer, more efficient and less expensive alternative to physicochemical methods for pollution abatement had been realized and play a crucial role in biogeochemical cycles for sustainable development of biosphere [21,22]. Microorganisms have the capacity to get adapted to the changes in the environmental conditions even at extreme environment [23, 24]. Microorganisms from soil and aquatic habitats are continuously exposed to different types of chemicals. These chemicals vary in physicochemical properties. These pollutants are known to interfere with metabolic processes of the organisms. They induce or inhibit many microbial enzymes. Among these chemicals various aromatic compounds are reported to interact with biotransformation and antioxidant enzymes in microorganisms. These microorganisms normally involved in degradation of such chemicals. Aniline is an aromatic substance used in various chemical industries. The presence of aniline in the environment is potential threat to living organisms. The degradation of aniline by neutrophilic bacteria have been studied by various reporters [25-27]. The degradation of aniline in alkaline conditions were earlier reported [28, 29], still the degradation of aniline by Bacillus badius D1 can't be compared with it due to little different experimental condition.

In the present study the degradation of aniline by Bacillus badius D1 was studied in various experimental conditions like concentration, $\mathrm{pH}$, temperature, salinity, additional carbon and nitrogen sources. The effect of initial aniline concentration on the degradation has shown that at lower concentration the rate of degradation is higher. Decrease in the rate of degradation at higher concentration may be due to toxic effects [30] of aniline with regard to inadequate cell/aniline ratio or biomass through the inhibition of metabolic activity. Similar results were observed in various reported microorganisms [31,32]. Our data indicates that the 
studied alkaliphile, Bacillus badius D1 strain can degrade aniline more efficiently than the earlier reported neutrophilic bacteria [33-34]. The degradation rate of aniline was found to be varied with various $\mathrm{pH}$ ranging from 7.0 to 11.0. At $\mathrm{pH} 9.0$ the degradation rate was maximum while the rate was marginally decreased with increase in $\mathrm{pH}$ indicating that the alkaliphile, Bacillus badius D1 strain degrade aniline in a wide range of $\mathrm{pH}$, while most of the neutrophilic bacteria degrade organic compound at neutral pH. Similarly, the effect of temperature on the degradation of aniline revealed that the bacterial strain could degrade aniline significantly in a wide range of temperature $\left(20-40{ }^{\circ} \mathrm{C}\right)$ indicating no thermal inactivation of bacterial degradation activity at 40 ${ }^{0} \mathrm{C}$. Further increase in temperature resulted in a decreased degradation rate [35]. The optimum degradation temperature [36] observed at $30{ }^{\circ} \mathrm{C}$. The degradation potential of this bacteria has been also studied in the presence of various salinity with additional carbon and nitrogen sources. Significant increase in degradation was observed in the presence of 0.5 to $2.5 \%$ salinity, with all added carbon and nitrogen sources. The ability of Bacillus badius D1 strain to degrade aniline even at a higher \% of salinity suggest that the strain is halotolerent [37] and can be used to treat the effluent containing high amount of salinity. All additional carbon sources were effective in acceleration of percentage degradation $[38,35]$. Similar results also observed in case of inorganic nitrogen sources. Additional carbon and nitrogen sources can generate NADH which acts as electron donors for hyrdroxylation of aromatic compounds by microbial enzymes.

Incubation of bacterial strain with aniline has been resulted in the increase in the activity of acetanilide hydroxylase, superoxide dismutase, catechol 1,2 dioxygenase and catechol 2,3 dioxygenase and cytochrome P450. The induction these enzymes might be due to the effect of parent molecule aniline or its metabolites on genes for coding these enzymes. In order to reveal the mechanism of degradation of aniline by an alkaliphile, Bacillus badius D1 strain, the structure of metabolites formed during biotransformation were delineated and elucidated the probable degradation pathway [39-42] of these molecules by various spectroscopic methods.

\section{Conclusion:}

The alkaliphile, Bacillus badius D1 strain was isolated from pristine Crater Lake of Lonar (MS) India, has strong aniline degradation potential. As it tolerates a broad range of temperature, $\mathrm{pH}$, salinity and concentrations, further adaptation of this strain may be useful for the commercial bioremediation purpose at polluted industrial site.

\section{Acknowledgement:}

This study was supported by UGC New Delhi, India

\section{References:}

[1]. H. Al-Awadhi \& Rasha H. D. Sulaiman Huda M. Mahmoud \& S. S. Radwan, Alkaliphilic and halophilic hydrocarbon-utilizing bacteria from Kuwaiti coasts of the Arabian Gulf, Appl. Microbiol. Biotechnol, 77 (2007) 183-186

[2]. Marı Teresa Garcia, Encarnacion Mellado, Juan Carlos Ostos and Antonio Ventosa, organivorans sp. nov. a moderate halophile able to degrade aromatic compounds, International Journal of Systematic and Evolutionary Microbiology 54 (2004)1723-1728.

[3]. Dimitry Y. Sorokin, Sander van Pelt, Tatjana P. Tourova, and Gerard Muyzer, Microbial Isobutyronitrile Utilization under Haloalkaline Conditions, Applied and Environmental Microbiology, 73( 2007) 5574-5579.

[4]. Isao Yumoto, Kikue Hirota,Yoshinobu Nodasaka,Yutaka Tokiwa and Kenji Nakajima, Alkalibacterium indicireducens sp. nov., an obligate alkaliphile that reduces indigo dye, International Journal of Systematic and Evolutionary Microbiology 58 (2008) 901-905

[5]. Victor M. Luque-Almagro, Marı a J. Huertas, Manuel Martı 'nez-Luque,Conrado Moreno-Vivia M. Dolores Rolda nL. Jesus Garcia-Gil, Francisco Castillo, and Rafael Blasco,Bacterial Degradation of Cyanide and Its Metal Complexes under Alkaline Conditions, Applied and Environmental Microbiology, 71 (2005) 940-947.

[6]. Kikue Hirota, Keiko Yamahira, Kenji Nakajima, Yoshinobu Nodasaka,Hidetoshi Okuyama, and Isao Yumoto Pseudomonas toyotomiensis sp. nov., psychrotolerant facultative alkaliphile that utilizes hydrocarbons, IJSEM Papers in Press. Published September 3, 2010 as doi:10.1099/ijs.0.024612-0

[7]. Josef Zeyer, Alain Wasserfallen, Kenneth N. Timmis, Microbial Mineralization of Ring- Substituted Anilines through a OrthoCleavage Pathway, Applied and Environmental Microbiology, 50(1985) 447-453.

[8]. R. J. Brennan and R. H. Schiest, Aniline and its metabolites generate free radicals in yeast, Mutagenesis, 12 (1997) 215-220.

[9]. Sarfraz Ahmed, Safia Ahmed, Muhammad, Farrukh Nisar,Khalid Hussain, Abdul Majeed, Isolation and characterization of a bacterial strain for aniline degradation, African Journal of Biotechnology, 9 (2010) 1173-1179.

[10]. Lowry H.O, Rosboough, N. j .Farr, A.L. and Randall R.J. 'Protein determination by Oliver H. Lowry' Journal of biological chemistry, 193(1951) 265-275.

[11]. Omura T. and Sato T.R., The Carbon Monoxide-binding Pigment of Liver Microsomes, J. Of Biol.Chem, 239 (1964) $2370-2378$.

[12]. Suk-Jung Choi, Mira Kim, Sung-Il Kim and Joong-Kyun Jeon, Microplate Assay Measurement of cytochrome P450-Carbon Monoxide Complexes, Journal of Biochemistry and Molecular Biology, 36( 2003) 332-335.

[13]. Misra H.P. Fridivich I, The Role of Super oxide Anion in the autoxidation of Epinephrine and a Simple Assay for Super oxide Dismutase, J. Biol.Chem, 247 (1972) 3170-3175.

[14]. Shenkman J. B Remmer H., Estabrook R.W, Spectral studies of drug interaction with hepatic microsomal cytochrome, Mol Pharmacology, 3(1967)113-123.

[15]. Weisburger and Goodal, Steric inhibition of enzyme reactions. Lack of enzymic hydrolysis of 2, 4,6 trimethylacetanilide, Life Sciences. (1968) 263-268.

[16]. Guzik Urszula; Gren Izabela; Wojcieszyska Danuta; abuek Sylwia, Isolation and characterization of a novel strain of Stenotrophomonas maltophila possessing various dioxygenases for monocyclic aromatic hydrocarbon degradation, Brazilian Journal of Microbiology 40 (2009) 285-291. 
[17]. M. Grekova-Vasileva, Y. topalova, Enzyme activities and shifts in microbial populations associated with activated sludge treatment of textile effluents, Biotechnol. \& Biotechnol. eq. 23(2009)1136-1142.

[18]. Jose M. Sala -Trapet and W. Charles Evans, The meta Cleavage of Catechol by Azotobacter Species 4-Oxalocrotonate Pathway, Eur. J. Biochem. 20 (1971) 400-413.

[19]. George Norwitr and Peter N. Kellhe, Spectrophotometric Determination of Aniline by the Diazotization-Coupling Method with N-( 1-Naphthy1)ethylenediamine as the Coupling Agent, Analytical chemistry, 53( 1981) 1238-1240.

[20]. Andrew McCartor, J.D.Dan Becker, B.A, Worlds worst pollution problems, Blacksmith Institute's Report, Fifth Avenue New York, NY 100351, 212 (2010) 647-830.

[21]. Tropel D.and Vander Meer J. R, Bacterial transcriptional regulators for degradation pathways of aromatic compounds, Microbiol.Mol.Biol. Rev, 68 (2004)474-500.

[22]. Shelly Sinha,Pritam Chattopadhaya,Ieshita, Pan Sandipan Chattergy et.al, Microbial transformation of xenobiotics for environmental bioremediation, African Journal of Biotechnology, 8 (2009) 6016-6027.

[23]. Kim J.S. and Crowley D.E, Microbial diversity in natural asphalts of the Rancho La Brea Tar Pits, Appl. Env. Microbiol,73 (2007) 4579-4591.

[24]. Diaz E and Prieto MA, Bacterial promoters triggering biodegradation of aromatic pollutants, Curr.Opin. Biotech, 11( 2000) 467475 .

[25]. Z. Liu H. Yang - Z. Huang - P. Zhou - S.-J. Liu, Degradation of aniline by newly isolated, extremely aniline-tolerant Delftia sp. AN3, Appl Microbiol Biotechnol 58(2002) 679-68.2

[26]. Chengbin Xiao, Jun Ning, Hai Yan, Xudong Sun and Jiye H U, Biodegradation of Aniline by a Newly Isolated Delftia sp. XYJ6 Chinese Journal of Chemical Enginering, 17 (2009) 500-505.

[27]. M. S. Sheludchenko, M. P. Kolomytseva, V. M. Travkin,V. N. Akimov, and L. A. Golovleva,Degradation of Aniline by Delftia tsuruhatensis 14S in Batch and Continuous Processes, Applied Biochemistry and Microbiology, 41( 2005) $465-468$.

[28]. Qiong Jin, Zhongce Hu, Zanfang Jin, Lequan Qiu, Weihong Zhong, Zhiyan Pan, "Biodegradation of aniline in an alkaline environment by a novel strain of the halophilic bacterium, Dietzia natronolimnaea JQ-AN" Bioresourc technology, 117,( 2012) $148-154$.

[29]. Junmin Li Zexin Jin, Binbin Yu, Isolation and characterization of aniline degradation slightly halophilic bacterium,Erwinia sp. Strain HSA 6, Microbiological Research, 165 (2010) 418-426.

[30]. R. Campbell Wnndham, Evolved Aniline Catabolism in Acinetobacter calcoaceticus during Continuous Culture of River Water, Applied and Environmental Microbiology 51(1986) 781-789.

[31]. Li Wanga, Suzelle Barringtonb, Jin-Woo Kim, Biodegradation of pentyl amine and aniline from petrochemical wastewater, Journal of Environmental Management 83 (2007) 191-197.

[32]. Nwodo Chinedu Shalom, O. Amund Olukayode, Biodegradation Potential of Two Rhodococcus Strains Capable of Utilizing Aniline as Carbon Source in a Tropical Ecosystem, Res. J. Microbiol., 3(2008) 99-104.

[33]. Guo Xia Zhang,Sui Zhou Ren, Guo Ping Sun et al;Rhizobium borbori sp. nov., an aniline-degrading bacterium isolated from activated sludge, IJSEM, Papers in Press. Published May 7, 2010 as doi:10.1099/ijs.0.022228-0

[34]. Teruo Tanaka, Hideo Hachiyanagi, etal;Biodegradation of endocrine disrupting chemical aniline by microorganisms, Journal of health science, 55(2009) 625-630.

[35]. Rensheng Zhuang, Wenhuizhong,Junyao,Huiluilun Chen, Lintian, Yongzhou, Feiwang, Emilia Bramanti and Gyulazaray, Isolation and characterization of aniline-degrading Rhodococcus sp. strain AN5, Journal of Environmental Science and Health Part A ,42 (2007) 2009-2016.

[36]. Chengbin XIAO Jun NING, Hai YAN, Xudong SUN' and Jiye HU, Biodegradation of Aniline by a Newly Isolated Delftia sp. XYJ6 , Research Center for Eco-Environmental Sciences, Chinese Academy of Sciences, Beijing 100085, China,2009

[37]. Tian Li \& Xin-Ping Deng \& Jin-Jun Wang \& Hui Zhao \& Lei Wang \& Kun Qian, Biodegradation of 3,4-Dichloroaniline by a Novel Myroides odoratimimus Strain LWD09 with Moderate Salinity Tolerance, Water Air Soil Pollution, 223 (2012) $3271-3279$.

[38]. Alisa S. Vangnai\& Wansiri Petchkroh, Biodegradation of 4-chloroaniline by bacteria enriched fromsoil,, Environmental Management, National Research Center for Environmental and Hazardous Waste Management, Chulalongkorn University, Bangkok, Thailand, (2007) 1-8.

[39]. Carolyn D. Lyons, Staanley Katz, and Richard Bartha, Mechanisms and Pathways of Aniline Elimination from Aquatic Environments, Applied and Environmental Microbiology, 48 (1984) 491-496.

[40]. Liang Quanfeng, CHEN Ming, XU Yuquan, Zhang Wei, Ping Shuzhen, LU Wei, Song Xianlong, Wang Weiwei, GENG Lizhao, Takeo Masahiro, LIN Min, Functional identification of gene cluster for the aniline metabolic pathway mediated by transposable element, Chinese Science Bulletin, 50 (2005) 1612-1614.

[41]. Prashant Kumar Jaiswal, Shweta Kohli, Madhuban Gopal, Indu Shekhar Thakur, Isolation and characterization of alkalotolerant Pseudomonas sp. strain ISTDF1 for degradation of dibenzofuran, J. Ind. Microbiol. Biotechnol,(2010)1007DOI 10.1007/s10295010-0793-7

[42]. Masaaki Urta, Eiji Uchida, Hideaki Nojiri, Toshio Omuri, Rie Obo, Genes involved in aniline degradation by Delfia acidovorans strain $7 \mathrm{~N}$ and distribution in natural environment, Bioscience, Biotechnol. Biochem 62(2004) 2457-2465. 